\title{
LET THEM WRITE ENGLISH
}

\section{O INGLÊS PARA TODOS}

Elise Langdon-Neuner ${ }^{1}$

The harsh words 'Let them eat cake' is the response attributed to Marie-Antoinette (1755-93), the Queen consort of Louis XVI, when she was told that the French populace had no bread to eat. At this time French was perhaps the most important language of science. Marie-Antoinette was later guillotined by the French populace. A lack of understanding for the difficulties faced by others does not apparently always serve oneself, something to be kept in mind when considering the demands for publication in English as the current language of science.

In 1995 there were an estimated 1113 million native speakers of Chinese and 372 million native speakers of English. Currently the number of Chinese native speakers is set to increase while that of English is set to decrease. By 2050 English is forecast to slip to position four on the list of numbers of native speakers between the ages of 15 and 24 years, with Spanish in a close fifth place and Portuguese in a not so close sixth place. Chinese will remain number one, Hindi/Urdu will move into position two and Arabic into position three ${ }^{1}$.

The United Kingdom (UK) recently imported 100 Mandarin teachers directly from China to meet the growing demand from pupils to learn a language that they believe holds the key to future global prosperity ${ }^{2}$. Nevertheless from today's viewpoint English is well established as the language of science and it is difficult to imagine how Chinese, with its script, could dislodge it. Whether they like it or not, scientists who do not publish their work in English exclude their work from the world's pool of knowledge, cut themselves off from discourse with fellow scientists internationally and run the risk that their careers in their own country will be stunted. Increasingly scientists' institutions and grant authorities throughout the world judge scientists' performance on their publications in Science Citation Indexed journals, few of which are published in languages other than English. Language, however, is not just a problem for the scientist alone. Progress in science throughout the world is hindered when research conducted in countries where English is not the native language is excluded from the pool of scientific knowledge. Only one-tenth of scientific journals published in Eastern Europe are published in English ${ }^{3}$. Russia is one of the world's leaders in per capita number of doctors and scientists, yet its literature is largely inaccessible to the rest of the world.
Authors whose first language is not English therefore need to publish in English. To do this they can .

- either learn English and pay an author's editor to check the English because, as discussed later, they rarely feel confident enough in English or if they do journals will ask them to have their English checked anyway or

- write in their own language and pay a translator

These authors should be supported in their efforts to contribute to the world's resource of scientific knowledge by.

- their own institutions, grant agencies and governments community

- organisations funded by the international scientific

- biomedical journals.

\section{LEARNING ENGLISH}

The ease with which a scientist learns English depends on the attitude of the culture he or she grows up in. In small countries where the native language is primarily only spoken by inhabitants of that country, e.g. in Finland, there is a stronger incentive to learn English. This is reinforced by exposure to English television and films that only have subtitles in the native language rather than being dubbed into that language, and by higher education often being conducted in English. However, the number of people speaking the native language is not the only factor. History is another. In India schools that teach in English are favoured and many speakers of Hindi are growing up speaking English. Where English has not been taught in schools, e.g. in Eastern Europe during the communist era, the current generation is especially disadvantaged.

Learning English as a second language might not always be enough. Ulrich Ammon, professor of German linguistics at the University of Duisburg, is quoted as saying "No one German is entirely comfortable speaking and writing in English"4. I can verify this from my experience working with Austrian scientists. Austrians have a positive attitude towards learning languages. Job prospects are believed to be greatly enhanced if you can speak English fluently and in addition have a good working knowledge of a second foreign

1. E. Langdon-Neuner is the editor of The Write Stuff, which is the journal of The European Medical Writers Association (EMWA), and a member of the editorial board of European Science Editing, which is the journal of The European Association of Science Editors (EASE). She has a BSc in zoology and was formerly managing editor of Diabetologia and The Journal of Men's Health and Gender. She currently works as an author's editor at Baxter BioScience, Vienna, Austria.

Recebido em 11/06/2007

Aceito para publicação em 16/07/2007

Conflito de interesses: nenhum

Fonte de financiamento: nenhuma 
language. Nevertheless authors feel more comfortable when an author's editor checks manuscripts they have written in English. Korean researchers and engineers who had learnt English and worked in the UK have said they miss more than $50 \%$ of what they hear during discussions with fellow experts ${ }^{4}$ . The move in Japan for science societies to hold their meetings in English has also been criticised because participants are less active than when discussions are held in Japanese ${ }^{4}$.

John Benfield, an Austrian-born American editor and professor of thoracic surgery at the University of California at Los Angeles, studied 50 consecutive manuscripts about lung cancer that came from authors whose first language was not English. This study included comments and all correspondence between the editor and authors ${ }^{5}$. He has also given courses on manuscript writing in the United States (US), Japan and China jointly with an English language professional, Christine Feak, from the University of Michigan. Benfield is convinced that authors whose first language is not English are disadvantaged by inability to say what they want to say in English as well as a native speaker of English would say it, or as well as they could say it in their own language. The disadvantage is particularly great when addressing controversial matters or subtleties (John Benfield, personal communication June 2007). I believe that people who are not native speakers of English - and sometimes those who aremay not always fully appreciate the nuances of a particular word they use. For instance when it comes to protecting its industry the US pays great attention to words. Objections were raised by the US delegation to the word 'code' at a recent World Health Assembly. A resolution had called for a 'code' to promote responsible marketing of foods and beverages to children. The US delegates objected to the word 'code' and proposed the phrase 'a set of recommendations'. Their objection to 'code' was that they felt it could be construed as being binding ${ }^{6}$. Pharmaceutical companies pay marketing agencies large sums of money to come up with brand phrases for their products that will appear in all their promotional material for that product, including articles published in biomedical journals. The subtleties of these phrases need to be fully understood by researchers who approve and put their names to the articles.

Far-reaching questions can arise when all scientists are forced to use English. Many Dutch university courses are now taught in English for the benefit of the foreign students that Holland attracts and is keen to attract. Literacy in English is high in Holland but even so teaching science in English puts an extra burden not only on Dutch students but also on professors because they cannot be as free and creative in a second language as in their first language, and they often have to oversimplify ${ }^{7}$. Furthermore when people regard their own language as inferior to the majority language they stop using it. This statement made in the context of projections that half of the world's estimated 5,000-7,000 languages will be lost by the end of this century ${ }^{8}$ also applies to science. Finnish academics are reported to contend that if university research focuses exclusively on the use of English, their own language will lose its ability to depict new concepts and phenomena and their subtle differences ${ }^{4}$.
Education in English has disadvantages for society too. Only the good scientific brains from the class that can afford such education will be captured, leaving good scientific brains from the pool of people who have not been so privileged untapped. A communication rift also arises in conveying science to practitioners and the general public. Review articles and articles informing professionals about new developments in their field are preferable in the native language of those readers, likewise information and news read by the general public. Healthcare is purportedly the most searched subject on the Internet. A new field where native language is important is that of 'knowledge translation'. The aim here is to is to bridge the so called "know-do" gap and get research results transformed into policies and practice. Putting knowledge into practice requires adapting it to local culture, and language is a key element of this (Hooman Momen, personal communication June 2007).

As long as English remains the world language of business and science bilingual education in state schools from primary education onwards, as my children have experienced, would appear to be a solution. To date there are still only very few schools even in Austria that have taken this route. From the state's view the cost of having two teachers in the classroom for every subject has to be balanced against that of teaching English for a particular purpose, e.g. science, and of translation. But the cost to the country's lost progress and development should also be taken into account.

\section{ASSISTANCE FROM AUTHOR'S EDITORS AND TRANSLATORS}

Authors who write in English can seek the assistance of an author's editor to check the text for language errors and polish the writing style to fit that of the journal targeted for publication of the article. The ideal author's editor would need to be an English linguist, have a good knowledge of the author's native language and understand the science as well. If the author writes in his or her first language for publication in English, likewise the ideal translator sought by the author should not only be qualified to translate between the languages but would also need to be trained in the science. Multitalented people are rare and expensive as is the alternative of two experts helping the author and working together, one on the language side and the other on the science side. However, such joint efforts have been found to yield better scientific reporting than peer editing or language professional editing alone $e^{9-12}$. The new European guidelines drawn up by the European Committee of Standardisation state that translations should optimally be reviewed by a specialist in the field, e.g. a physician for a biomedical translation (www.lisa.org/globalizationinsider/ 2005/04/the_en15038_eur.html).

One thing that should not be forgotten is that translators and editors introduce their own subjectivity. The content and emphasis of a translation cannot be assumed to be the same as that of the original, just as the claim that editing is merely helping authors say what they mean is not reliable. A study of abstracts written in French, translated into English by two French authors and then edited by two English native 
speakers found the editors imposed their own styles of writing and changed the original meaning in different ways. Furthermore readers recognised the abstracts as having different "voices'"13.

\section{WHO PAYS FOR COURSES AND ASSISTANCE ?}

Authors can be helped by their institutions setting aside funds for courses to improve their English. For example a new medical curriculum was approved in Serbia in 2004 in which medical students are required to take two compulsory courses in medical English and are also given the opportunity to attend three elective courses. Tuition, however, needs to extend beyond English. Editors of the Croatian Medical Journal $(C M J)$ have found that language is not the main problem with manuscripts submitted to their journal, which is published in English. Authors also need training in planning and performing the study, writing the narrative, and in scientific reporting style. The $C M J$ has been running courses for physicians and postgraduate students covering these aspects as well as English language since December $2000^{7}$.

Sometimes fees paid to translators or author's editors are met by the scientist's institution or from research grants, but very often scientists have to pay themselves. Scientists' institutions or grant agencies could support authors by meeting the cost of author's editors or translators and by establishing links with high quality suppliers. When I asked for information on the European Science Editors (EASE) online forum (www.ease.org) the replies gave the impression that the number of commercial organisations offering manuscript services have greatly mushroomed over the past few years, especially in Eastern European countries such as Hungary. From Poland the warning came that it is usually not easy to find a good translator specialising in one's field, while nonspecialist translators do not understand the text and make many mistakes. Authors everywhere should carefully scrutinise the qualifications of service providers and the quality of the work they produce.

Gradually the international scientific community is obliging with programmes of assistance. Examples of programmes financed by the international community to help authors include the AuthorAID project ${ }^{14}$. In this project authors whose native language is English mentor and assist authors in Africa, Asia, Latin America and Eastern Europe with writing their papers. The project differs from international research collaborations where assistance comes from coauthors who also need to look after their own interests. Another example of a programme that helps authors in developing countries is run by the International Network for Cancer Treatment and Research (www.inctr.be) and financed by the US National Cancer Institute.

\section{THE ATTITUDE OF BIOMEDICAL JOURNALS}

Authors whose first language is not English but who write in English often believe that their manuscripts are less likely to be accepted by biomedical journals. However, data from the Annals of Thoracic Surgery indicate that the disadvantage is not in the incidence of ultimate publication but rather in the need to revise manuscripts ${ }^{5}$. Likewise a study in Cardiovascular Research which sought to pin-point language area problems that could effect the possibility of sound medical work being rejected found that poor writing was unlikely to result in outright rejection but that it may influence the overall impression of the work ${ }^{15}$. Certainly journals often ask authors to have their manuscripts checked for English if the corresponding author is located in a country where English is not the native language. Such requests are helpful if the language problems are specified but frequently the request is a standard response to the corresponding author's address. An example was given by a Spanish author who complained in a letter to Nature that almost all referee comments he received mentioned style. He asked a friend, who was a professor at Oxford University in the UK, to check his manuscript. The friend had published over 250 papers himself and was editor-in-chief of a reputed journal. However, even after his check one referee, without identifying errors, still demanded that the manuscript be revised by a native English speaker. The Spanish author suggested in his letter to Nature that an institute of correct English style should be established to which authors could send their manuscripts. The institute could correct the paper and certify its compliance to an accepted language standard ${ }^{16}$.

The Bulletin of the World Health Organisation publishes articles in English with abstracts in English, French, Spanish and Arabic, e.g. http://www.who.int/bulletin/volumes/ 85/5/06-038521.pdf. Hooman Momen, editor of the bulletin, believes that journals could be more sensitive to the needs of authors whose first language is not English. For example they could encourage authors to use standard phrases in the materials and methods, and results sections (without risking accusations of plagiarism), perhaps even compiling glossaries of appropriate phrases and terms for their speciality. Journals which have the resources of internal editors could also accept the discussion section in bullet point format and create the text for the author (Hooman Momen, personal communication June 2007). The website of The World Health Organization (WHO) can be viewed in six languages (http://www.who.int/ en/ ) and the organisation has shown its concern that research from all countries in the world should be published and understood by its commitment to multilingualism. A plan of action on multilingualism has recently been approved by the WHO_ (http://www.who.int/gb/ebwha/pdf files/EB121/ B121 6-en.pdf). The United Nations' General Assembly also recently passed a resolution on multilingualism (A/61/1.56 on 9 May 2007) and proclaimed 2008 “The International Year of Languages".

Large commercial English language journals such as The British Medical Journal, Lancet, Journal of the American Medical Association and Journal of the American Dental Association have been publishing editions translated into other languages for some years now. Moreover in the last few years a new trend of cover-to-cover translation of journals originally published in languages other than English has developed. Mary Ellen Kerans who heads the team of translators that 
translates Archivos de Bronchoneumología from Spanish into English explained in response to my EASE forum request that the purpose of bilingual publication of science is to bring a whole community of scientists closer to the centre of discourse and at the same time reinforce autochthonous language scientific activity. Higher education in that language is thereby strengthened in contrast to the weakening wrought by using English to teach science and medicine in countries like Holland. Brazil is one of the countries at the forefront of bilingual publication. Two approaches are being encouraged. In one, the print version of the journal is published in Portuguese only, but the online version is published in both Portuguese and English (e.g. Jornal Vascular Brasileiro and Revista de Psiquiatria do Rio Grande do $S u l$ ). In the other, both the printed and the online version have bilingual content (e.g. Jornal de Pediatria). Bilingual publication is currently limited by the considerable financial resources it requires but in the future this expenditure might be relieved by improved translation software.

\section{TRANSLATION SOFTWARE}

To date no translation software exists that substitutes for a human translator. The software is only an assistance to the human translator. Computer assisted translation (CAT) and machine translation (MT) need to be distinguished. CAT is a searchable corpus of validated translations which a human translator uses to produce translations from idiosyncratic texts such as that found in research manuscripts. With MT a draft is produced electronically, which a human translator brings up to publication standard by making sure terminology is accurate and style is followed. MT is more suited to structured and standardised phrases and terms, which is a reason for Hooman Momen's suggestion that journals use standard phrases in the materials and methods and results sections. There are some free MT tools (such as Babel Fish see http:// babelfish.altavista.com/). Google have also recently announced a new translation service (http:// s e a t t lepi.n w s o r c e.com/busines s/ 316982_googletranslation24.html). When the progress in computer software over the last 20 years is considered it is not hard to imagine that translation software could be developed in the not too distant future to such a quality as to require little intervention by human translators. Multilingual publication would then become more affordable.

\section{CONCLUSION}

The current hegemony of English as the language of science places authors who do not speak English as a first language at a disadvantage. This disadvantage can be alleviated by training in scientific English together with instruction on writing scientific manuscripts. Author's editors and translators can also be of assistance. A good approach is for two native speakers of English to check a manuscript, an expert in English linguistics and an expert in the particular scientific field. Journals could also be more helpful to authors whose first language is not English.

Costs of training, editing and translation services should be met by the author's institution or funding agency to enable the research to become part of the international pool of scientific knowledge. Some international organisations also provide support. Learning English and the use of author's editors or translators are not a guarantee that the subtleties of meanings are correctly transferred from the original language into English. Particular care is needed if the author's editor or translator is being paid by a party with a vested interest in the research.

Despite the current international use of English to converse in science, other languages should not be excluded from science. Higher education solely in English can lead to a loss of ability to express new concepts and phenomena in the native language. Languages carry their culture with them and a hegemony of one language excludes a cultural diversity of attitude and thought that is critical to science.

Furthermore it is important to convey science to professionals and the general public in their native tongue. Bilingual education from an early age could be an ideal solution, but is still rare in practice. There is a new trend of cover-tocover translation of medical journals from the original language into English, but it is still expensive. Development of translation software may reduce cost in the future. The WHO has shown its dedication to multilingualism publication by its recent approval of a plan on multilingualism. Hopefully the coming year of international languages will increase awareness of the problems surrounding communication of science and promote a unified effort to pool world scientific knowledge in such a way as to preserve language and cultural diversity but at the same time ease accessibility for all.

\section{ACKNOWLEDGMENTS}

I would like to thank the following contributors to the EASE forum for information they provided for this article: John Benfield, Mary Ellen Kerans, Sywia Ulfnalska, Elisabeth Heseltine, James Hartley, Yateen Josh, Lorna O’Brien, Carol Norris, and Harvey Shenker. My thanks also to Hooman Momen, Françoise Salager-Meyer and Claudia Buchweitz.

\footnotetext{
ABSTRACT

This article discusses the current requirement for scientific research to be published in the English language and the problems arising from this requirement not only for authors whose first language is not English but also for society and for the world's scientific community. The assistance which is and should be available to authors is considered as well as a future looking towards multilingual publication (Rev. Col. Bras. Cir. 2007; 34(4): 272-276).
} 


\section{REFERENCES}

1. Graddol D. The Future of Language. Science. 2004;303:1329-31.

2. Frean A. 100 teachers imported from China. The Times, 24 May 2007.

3. Lysenko V. Inaccessible science literature in Eastern Europe. European Science Editing. 2007;33(1):10-12.

4. Lee La Madeleine B. Lost in translation. Nature. 2007;445:4545 .

5. Benfield JR, Howard KM, The Language of Science, Eur J Cardiothorac Surg. 2000;18(6):642-8.

6. Glusker A. Assembly gets into wrangle over junk food warning. BMJ. 2007;334:1130.

7. Vasconcelos SMR, Wu W, Ivanis A, Hull E, Handjani F, Barron JP, Salager-Meyer F. Around the world:Teaching medical writing to doctors and scientists. The Write Stuff. 2007;16(1):12-15.

8. Gibbs WW. Savings Languages. Scientific American. August 2002;63-9.

9. Parkhurst C. The composition process of science writers. English for Specific Purposes 1990:169-79.

10. Flowerdew J. Attitudes of Journal Editors to Nonnative Speaker Contributions. TESOL Quarterly. 2001;35:121-50.

11. Benfield JR. English for Chinese cardiothoracic surgeons. In: Wan S and Yim APC, editors. Cardiothoracic Surgery in China: Past, Present and Future. ShaTin, Hong Kong: The Chinese University of Hong Kong Press:2007. p. 507-19.
12. Benfield JR. Cardiothoracic surgeons divided by a common language, Ann Thorac Surg. in press.

13. Hartley J, Branthwaite A, Ganier F, Heurley L. Lost in Translation: Contributions of editors to the meanings of text. Journal of Information Science. Published Online on 10 April 2007 doi: 10.1177/0165551506076392.

14. Robbins A, Freeman P. AuthorAID: Developmental editing assistance for researchers in developing countries. European Science Editing. 2007:33(1);9-10.

15. Coates R, Sturgeon B, Bohannan J, Pasini E. Language and publication in "Cardiovascular Research" articles Cardiovasc Res. 2002;53:279-85.

16. Herrera AJ. Language bias discredits the peer-review system [letter]. Nature. 1999;397:467.

Como citar este artigo:

Langdon-Neumer E. Let them write English. Rev Col Bras Cir. 2007;34(4). Disponível em URL: www.scielo.br/rcbc

Correspondence to:

Elise Langdon-Neuner

Baxter BioScience

Wagramer Strasse 17-19

A-1220 Vienna, Austria

Phone: + 431201002067

Fax: + 43120100525

e-mail:langdoe@baxter.com 